\title{
Comparison of delay factors and remedies' rankings for building construction projects in developing countries
}

\author{
Raza Ali Khan ${ }^{1}$, Uneb Gazder ${ }^{2, *}$, Abdul Qayoom ${ }^{3}$ \\ ${ }^{1}$ Department of Civil Engineering, NED University of Engineering and Technology, Karachi, Pakistan \\ ${ }^{2}$ Department of Civil Engineering, University of Bahrain, Bahrain \\ ${ }^{3}$ Department of Civil Engineering, Shaheed Z. A. Bhutto Campus, Mehran University of Engineering and Technology, Khairpur \\ Mir's, Pakistan
}

\section{A R T I C L E IN F O}

\section{Article history:}

Received 12 December 2016

Received in revised form

27 February 2017

Accepted 3 March 2017

\section{Keywords:}

Delay

Remedies

Building projects

Stakeholder perception

Developing countries

\begin{abstract}
A B S T R A C T
In this research paper, the main causes and remedies to delays for building construction projects in Karachi are identified and ranked according to the viewpoint of all stakeholders using frequency indices. Furthermore, the ranking was tested statistically by using Analysis of Variance (ANOVA) and box plots. It was found that the perception of clients regarding causes of delays is different than other stakeholders. Whereas, consultant group's perspective about the remedies for delays was different than all others. Such studies have also been conducted in other regions of the world. However, a comprehensive review and comparison was not found in the existing literature. Therefore, the results were also compared with previous international studies conducted in other developing countries. It was found that the perception of local client group was greatly different in from that for other regions. On the other hand, the perception of contractors was found to be similar for local and other construction industries. On the basis of this study, it can be said the client group's perception is unique in Pakistan compared to other industry stakeholders, locally as well as internationally.
\end{abstract}

(c) 2017 The Authors. Published by IASE. This is an open access article under the CC BY-NC-ND license (http://creativecommons.org/licenses/by-nc-nd/4.0/).

\section{Introduction}

There are three criteria which account for project success; completion on-time, within budget, and in accordance with the specifications. In addition to that, stakeholders' satisfaction also plays a significant role in this regard. Construction project delays are the most commonly occurring issues worldwide (Majid and McCaffer, 1998). The magnitude of delay may vary from a few days to over a year which results in increase in costs as well. Hence, study of the actual causes of delays is essential to avoid delays or minimize its impacts in construction projects (Mezher and Tawil, 1998). The important issues to address are the main causes of delay and the possible remedies. Each stakeholder often has a different purview of these matters and puts the emphasis on the other party; for e.g. the contractor may blame client or consultant or architect and vice versa. These conflicts cause litigations and, sometimes, total abandonment of

\footnotetext{
* Corresponding Author.

Email Address: unebgazdar@gmail.com (U. Gazder) https://doi.org/10.21833/ijaas.2017.04.006

2313-626X/C 2017 The Authors. Published by IASE.

This is an open access article under the CC BY-NC-ND license

(http://creativecommons.org/licenses/by-nc-nd/4.0/)
}

project. The need for research in this area, in spite of a number of previous studies, has been identified by Chidambaram et al. (2012). They have presented a review of previous studies in an attempt to compile the causes of delays. However, they have surrendered to the fact that there is still scope for further research to determine the causes of delays in construction projects. This research study is aimed at determination of perspective of different stakeholders of building construction industry with regards to major causes and effects of delays and methods of minimizing them.

Mezher and Tawil (1998) investigated the causes of delays by conducting a survey in the construction industry in Lebanon from stakeholders firms. Each stakeholder had a different perspective with regard to the importance of causes of delays. Owners were more concerned with financial issues; contractors gave more importance to contractual specifications, while consultants rated project management issues highly among the causes of delays. In another study by Odeh and Battaineh (2002), the perception of causes of delay was found for contractors and consultants in Jordan. They found that inadequate contractor experience was commonly ranked high by both groups. Apart from that, labor productivity and owner interference was ranked more highly by 
contractors while delay in payments and subcontractors were ranked as prime causes by consultants.

There were some studies found for the Asian developing countries, which focused on determining overall ranking for causes of delays. Assaf et al. (1995) studied the large-scale building construction projects in Saudi Arabia with regards to causes of delays. The researchers identified that the most important causes of delay are related to provision of design and drawings including design errors, approval of shop drawings, and design changes. Other factors include executive bureaucracy in owner's organizations, and availability of skilled labor. Kumaraswamy and Chan (1998) indicated the following to be common causes of delays in Hong Kong; unexpected site condition, poor site management and supervision, poor coordination for decision making among all stakeholders, and scope variations.

Al-Momani (2000) reiterated the above points with the addition of increase in material prices, result in delay in payments and deliveries, as the cause of delay in Jordan. Other studies which have also found the above factors for causes for delays in other Asian countries include Kuwait (Koushki et al. 2005), Indonesia (Wiguna and Scott, 2003), India (Doloi et al. 2012), Sri Lanka (Halwatura and Ranasinghe, 2013), Egypt (Marzouk and El-Rasas, 2014) and Combodia (Santoso and Soeng, 2016). Wiguna and Scott (2003) and Santoso and Soeng (2016) also added weather conditions (or natural disasters) and litigations on substandard construction work to the main causes of delays. The later also argued that awarding contracts to lowest bidders results in substandard work which causes delays.

These factors have also been identified for many African developing nations including Nigeria by Albinu and Jagboro (2002), Tanzania by Kikwasi (2013), and Uganda by Alinaitwe et al. (2013). This could mean that litigation is a more significant issue in developing countries all around the globe. The above mentioned studies from African countries have also mentioned political instability and changes in regulations to be a major cause of delays as well. This situation is found similar to Pakistan.

In addition, Memon et al. (2012) attributed the delays to poor project documentation and financial management. Moreover, Doloi et al. (2012) mentioned poor communication between the project team members as the reason for delays in India. This was not mentioned in other studies as it is correlated with factors such as litigation, changes in scope, etc.

A comprehensive study for Karachi construction industry was found to be carried out by Farooqui et al. (2007), who investigated contractor's perception about causes of delays. The researchers found almost all the above mentioned factors to be responsible for delays, with the exception of poor communication, documentation, political instability and changes in regulations. However, more work is required for this area since this study only focused one group of stakeholders.

In the scenario of developed countries such as USA and Singapore, site management, coordination among various parties, design/scope changes by owner, availability of laborers, management staff on site, and contracting methods have been identified as the prime factors causing delays in construction (Herbsman et al., 1995; Hwang et al., 2013). Hence, it can be said that the delay causing factors are primarily the same in developed and developing countries. However, inflation, litigation and instability in political and regulatory scenarios are some of the problems which are found more commonly in developing countries across the globe.

The above studies show that material procurement and its relevant factors such as inflation in prices is significant contributor to delay in construction projects, especially for developing countries. In addition to that, poor scope management which often initiates litigation in the construction projects is another prime cause in this regard. However, some of these studies also show that the causes of delays are perceived differently with varying conditions.

This study addresses the important aspect of difference in perception of the causes/factors and remedies of delays by the stakeholders, which often leads to litigations in the construction projects. This fact has been accepted in previous studies but the literature on its statistical analysis is rarely found. Moreover, the review of comparison with the international scenario was also not found. Such investigation would help in devising an effective mechanism to overcome the problem of delays, especially in the settings of developing country like Pakistan. The results of this study are strengthened through statistical hypothesis testing which was done to explore the relationship and agreement or disagreement between the responses of the respondents from different stakeholder groups. This was done for causes as well as remedies for delays. The perception of different stakeholder groups regarding causes was also compared with previous studies found to determine the conformity in international scenario.

\section{Research methodology}

In this research, the information about causes and remedies of delays in building construction projects of Karachi (Pakistan) was collected through a questionnaire. The survey respondents belonged to different stakeholder groups including architects, clients, consultants and contractors. Questionnaire survey was conducted through postal mail and personal interviews in two phases. In the first phase, the respondents were requested to select the causes and remedies for delays from the available list which are experienced in local industry. The same respondents were asked to give feedback to rank the causes and remedies of delays in building construction projects of Karachi, Pakistan. 
The questionnaire was divided in to three (03) parts, namely; A, B and C. Respondent's professional information and company's profile were requested in part A. Part B focused on determining the ranking of causes of delays on a Likert scale from 1 to 5 where 1 means never and 5 means always. It contained eighty-one (81) factors which were identified through extensive literature review. These factors were classified into following eight (08) broad categories in light of previous studies:

1. Material-related Delays ( 9 causes)

2. Labor-related Delays (8 causes)

3. Equipment-related Delays (10 causes)

4. Financial-related Delays (8 causes)

5. Contractor-related Delays (13 causes)

6. Client-related Delays (14 causes)

7. Consultant-related Delays (11 causes)

8. External Environment Delays (8 causes)

Methods of minimizing construction delays (remedies) were ranked in Part D. There were 35 remedies identified based on the literature review with respect to Pakistan construction industry. These remedies were also ranked from 1 to 5 on Likert Scale where 1 show very low effect and 5 shows very high effect.

Questionnaire was tested through pilot survey, and then finally distributed amongst the major key players. Detailed interviews were also conducted to have a clear and broader perspective. The developed survey questionnaire was distributed to 80 different organizations (Contractors, Consultants, Clients and Architects). Out of 80, 58 organizations responded to the survey resulting in response rate of approximately $72 \%$. The breakdown of the responses is shown in Table 1.

Table 1: Breakdown of responses

\begin{tabular}{cccc}
\hline $\begin{array}{c}\text { Type of } \\
\text { Organization }\end{array}$ & Approached & Responded & $\begin{array}{c}\text { Responses } \\
\%\end{array}$ \\
\hline Architects & 14 & 8 & $57.14 \%$ \\
Clients & 15 & 9 & $62.5 \%$ \\
Consultants & 21 & 15 & $73.33 \%$ \\
Contractors & 30 & 26 & $88.0 \%$ \\
\hline
\end{tabular}

The collected response data was analyzed to find the top-ranked causes and remedies of delays for construction industry in Pakistan. Ranking of the causes was also compared with the international literature for stakeholder perception. Statistical techniques used in this research included, Analysis of Variance (ANOVA) Technique and box plots which were used to analyze difference in perceptions of stakeholders regarding causes and remedies of delays.

\section{Results and discussion}

For data collected in Part B of questionnaire, Frequency Index (FI) was used. This index is used to rank the causes of delays based on frequency of occurrence as identified by the client, consultant, contractor and architect. FI can be calculated using Eq. 1.

$F . I=\sum\left[a\left(\frac{n}{N}\right) \times \frac{100}{5}\right]$

Where, $a$ is the weight given in each response to the particular factor (ranges from 1 for rarely up to 5 for always), $\mathrm{n}$ is the frequency for response ' $\mathrm{a}$ ' and $\mathrm{N}$ is total number of responses.

\subsection{Stakeholders' perspective on common causes of delays}

Table 2 shows the top ten factors causing delays identified by each stakeholder on the basis of FI. The values are arranged in descending order of FI. It can be observed that factors related to finance are ranked higher by architect. These include allocation and availability of funds. Moreover, a change in design (which is often initiated by the change in scope from the client) is also ranked higher by the architects as the recurring cause of delay. These were found to be the top three (03) ranked causes of delay by the architect. Hence, the architect perceives that the project would have lesser number and impact of delays if the funds and scope is managed properly by the client.

According to client, escalation in market prices, slow mobilization of labor and improper scheduling and planning are the most recurring causes of delays. Escalation of prices affects the cash flow requirements of the project resulting in delays. It can also be linked to the observation from architect's group in which funds availability was found to be a major cause for delay. Mobilization of labor is the responsibility of contractor while project planning and scheduling is done by the design or project management consultants. Hence, it can be said that the client does not perceive any single party to be a major contributor in the delays of the projects.

The consultant group has ranked unreliability of supplier, inadequacy of contractor's experience and the lowest bidder selection method in procurement to be the major causes of delays. All these issues are related to the selection of contractors/subcontractors and suppliers which is specified/supervised by the client. Therefore, the consultants perceive that the projects can run smoothly without delays if proper selection procedures are adopted/specified by the clients for team building.

The contractor group has rated change orders, delay in payments and inaccurate estimation of project duration to be major causes of delays. Change orders may be initiated by any of the project stakeholders due to change in scope, unexpected field conditions or change in specifications. Frequent design changes were also ranked higher by the architects' group as well. Hence, it can be said that contractors put more emphasis on the accurate design of project based upon field observations. Delay in payments is linked to the availability of 
funds and escalation of prices which is also ranked higher by architects and clients groups. Inaccurate estimation of time can also be linked to the improper project planning and scheduling which was ranked higher by the clients' group as well. From these observations, it can be said that perspective of contractors' group is more linked to architects and clients as compared to consultants. Similar to clients, contractors have also not shown tendency to rank those factors higher which are related to a particular stakeholder.

\subsection{Comparison with international scenario}

The authors were able to find some studies in which causes of delays were ranked by different stakeholder groups. Mezher and Tawil (1998) carried out their study in Lebanon while Odeh and Battaineh (2002) conducted similar study for Jordan. The former one did classified ranking for Contractor,
Owner (clients) and Architect/Consultant group while Odeh and Battaineh (2002) only included contractor and consultant group. In addition, Farooqui et al. (2007) also investigated the rankings of causes of delays from the perspective of contractors in Pakistan. In this study, we compared the ranking of the top 10 causes (as shown in Table 2) for each stakeholder group with those found in this literature. The comparative results are found in Figs. 1-4.

It should be noted that this study contained a more comprehensive list of causes of delays than those found in the said studies. The list was extended through comprehensive literature and author's judgment of the local industry to incorporate perspective of all stakeholder groups. Hence some of the factors mentioned in this study were not found in these previous studies.

Table 2: Top ten factors causing delays

\begin{tabular}{|c|c|c|}
\hline Factors Causing Delay & Group & F.I. \\
\hline \multicolumn{3}{|c|}{ Architect's Perspective } \\
\hline Inadequate fund allocation & Finance & 205 \\
\hline Client's financial difficulties & Finance & 195 \\
\hline Frequent design changes & Client & 180 \\
\hline Inaccurate cost estimating & Contractor & 155 \\
\hline Constraints of client (bank loans, funds, taxes etc.) & Finance & 140 \\
\hline Monthly payment difficulties & Finance & 135 \\
\hline Misunderstanding owner's requirements/project scope & Consultant & 130 \\
\hline Incomplete construction drawings (shop drawings) & Contractor & 125 \\
\hline Improper project feasibility study & Client & 125 \\
\hline Delay payment to supplier/subcontractor & Finance & 120 \\
\hline Lack of communication/coordination & Client & 120 \\
\hline Inaccurate site investigation & Consultant & 120 \\
\hline \multicolumn{3}{|l|}{ Client's Perspective } \\
\hline Escalation of material prices & Material & 184 \\
\hline Slow mobilization of labor & Labor & 104 \\
\hline Improper project planning \& scheduling & Consultant & 100 \\
\hline Labor productivity & Labor & 92 \\
\hline Shortage of skill labor & Labor & 88 \\
\hline Poor site management and supervision & Consultant & 88 \\
\hline Delay in approving shop drawings and sample material & Client & 84 \\
\hline Frequent equipment breakdown & Equipment & 84 \\
\hline Constraints to client (bank loans, funds, taxes etc.) & Client & 84 \\
\hline Poor managerial and leadership skills & Consultant & 76 \\
\hline \multicolumn{3}{|l|}{ Consultant's Perspective } \\
\hline Unreliable supplier & Contractor & 260 \\
\hline Inadequate contractor's experience & Contractor & 260 \\
\hline Lowest bidding procurement method & Client & 236 \\
\hline Slow decision making by client & Client & 235 \\
\hline Poor design \& delays in design & Consultant & 231 \\
\hline Incomplete drawing/details design & Consultant & 231 \\
\hline Improper project planning \& scheduling & Consultant & 229 \\
\hline Unavailability of utilities on site & Consultant & 227 \\
\hline Shortages of equipment parts & Equipment & 225 \\
\hline Unexpected geological condition & External Environment & 225 \\
\hline \multicolumn{3}{|l|}{ Contractor's Perspective } \\
\hline Change orders & Finance & 567 \\
\hline Delay payment to supplier/subcontractor & Client & 547 \\
\hline Inaccurate time estimating & Consultant & 547 \\
\hline Lack of capable client representative & Client & 545 \\
\hline Slow decision making by client & Client & 506 \\
\hline Client's financial difficulties & Finance & 468 \\
\hline Frequent design changes & Client & 430 \\
\hline Constraints to client (bank loans, funds, taxes etc) & Financial & 418 \\
\hline Incomplete drawing/details design & Consultant & 414 \\
\hline Late in revising and approving design documents by the owner & Client & 409 \\
\hline
\end{tabular}




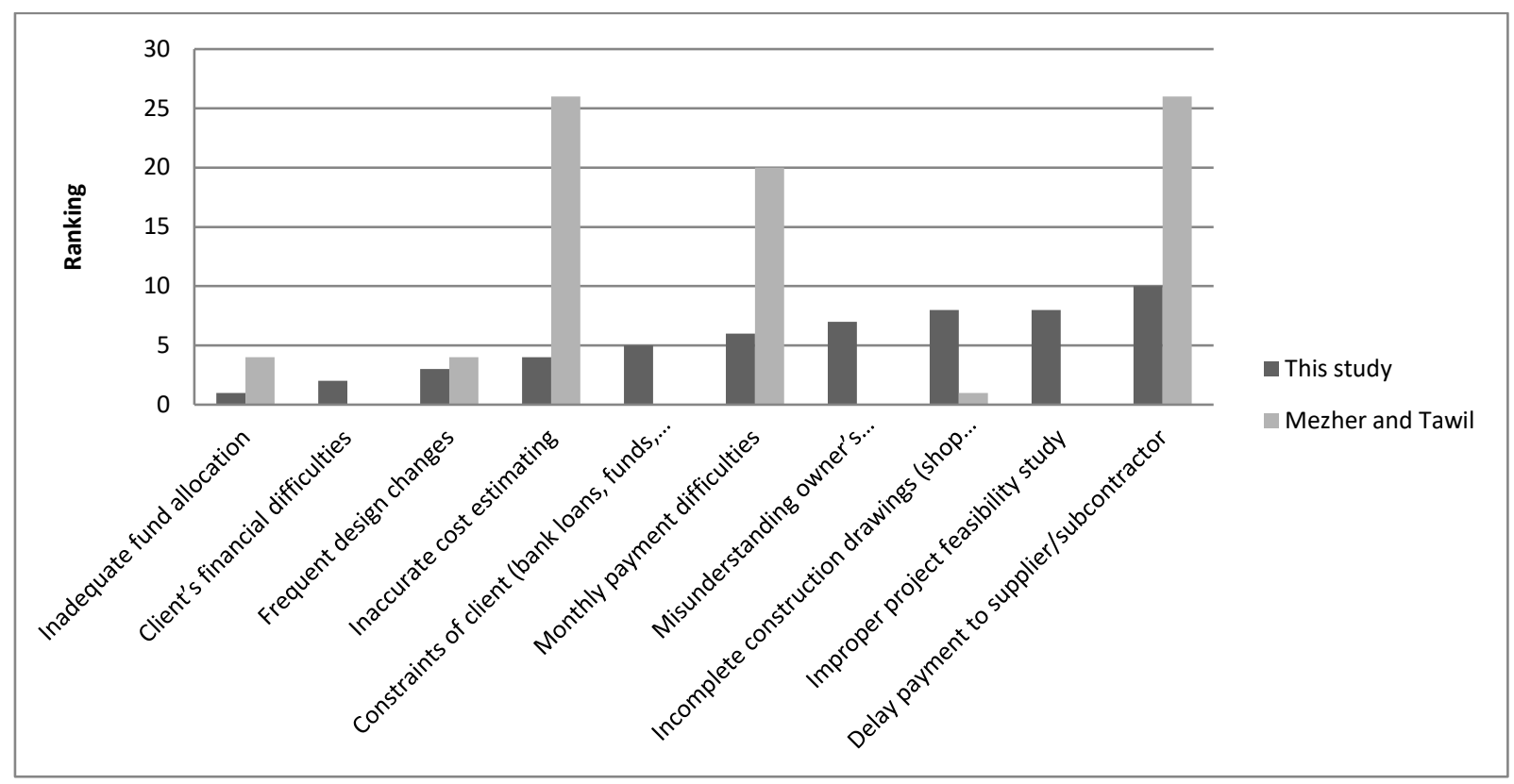

Fig. 1: Comparison of ranking for causes of delays by architects

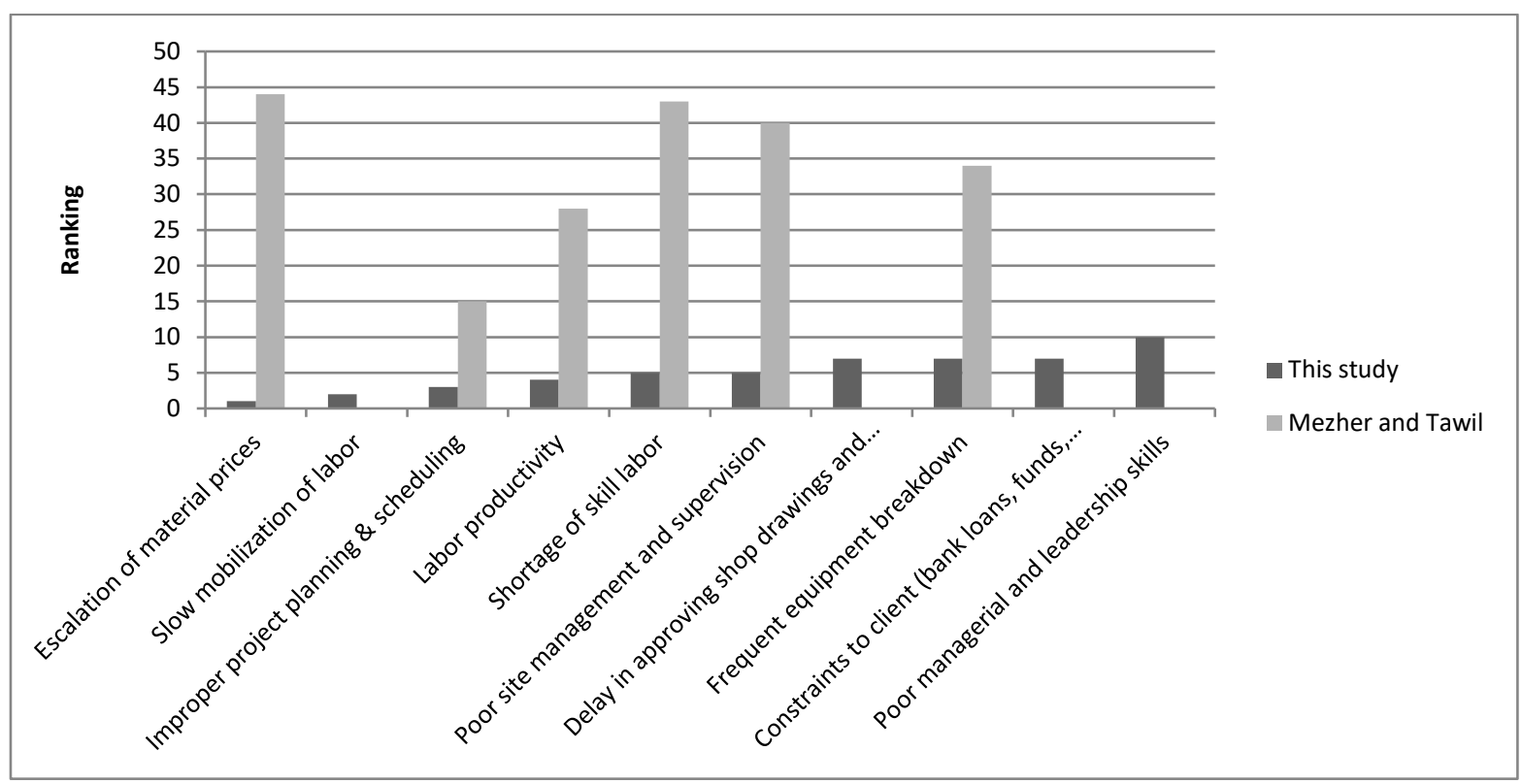

Fig. 2: Comparison of ranking for causes of delays by clients

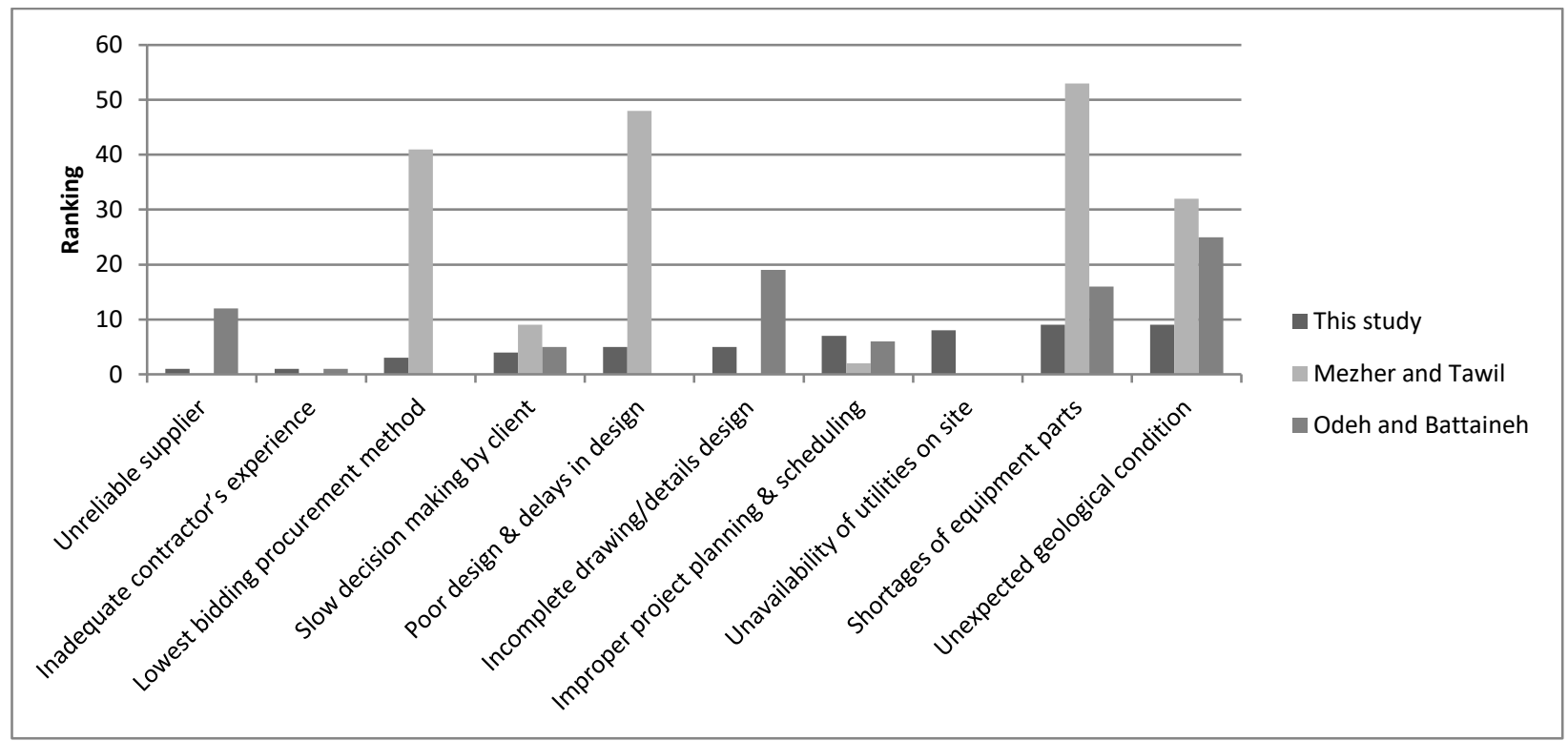

Fig. 3: Comparison of ranking for causes of delays by consultants 


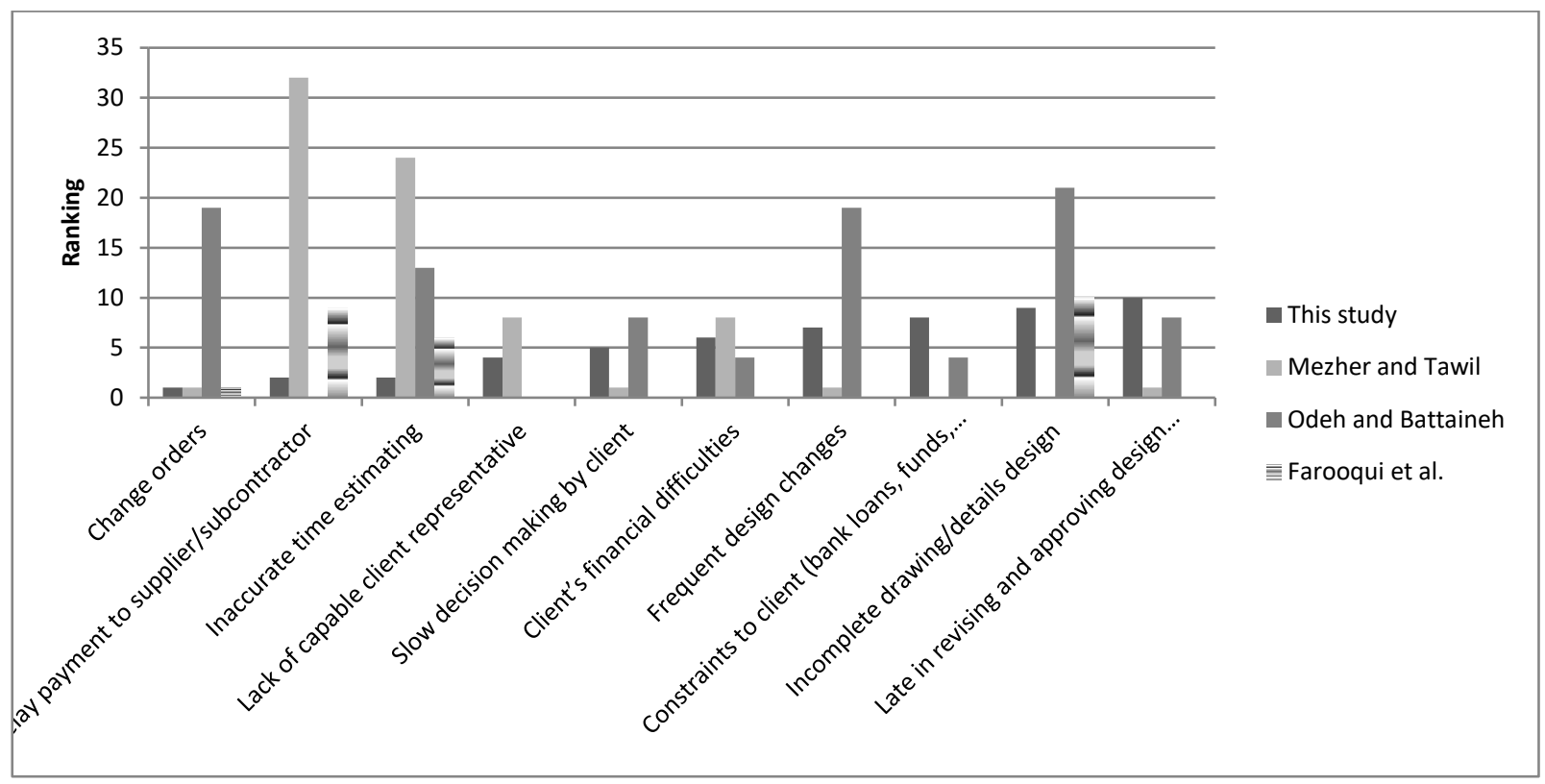

Fig. 4: Comparison of ranking for causes of delays by contractors

Data plotted in Fig. 1 shows the comparison of rankings by the architect groups. Inadequate funds allocation, frequent design changes and incomplete construction drawings were found to be the highly ranked factors in both studies. Apart from that, all other factors which were highly ranked by the architects in this study were either not found in the previous study or were ranked with low importance in the previous study.

Fig. 2 represents the comparison of ranking for the client groups. Out of top 10 ranked factors of this study, only 6 were found to be included in the previous study by Mezher and Tawil (1998). However, none of the factors from this study were found to be highly ranked by the client group in the said study.

The comparison of ranking by the consultant groups was available by Mezher and Tawil (1998) as well as Odeh and Battaineh (2002) as shown in Fig. 3. Inadequate experience of contractor was found to be the top ranked factor in this study as well as by Odeh and Battaineh (2002). Slow decision making by the client and improper project planning and scheduling was ranked among the top 10 causes by this study as well as both previous studies.

Comparatively highest conformity in rankings of causes was found to be for contractors group between this study and the previous studies. The data in Fig. 4 shows that six (06) factors were found to be ranked amongst top 10 in more than one study including the present one. These factors included; change order, lack of capable client representative (project manager), slow decision making by client, client's financial difficulties, and frequent design changes, constrains to clients and late in revisions and approval of drawings. There were more similarities in rankings of this study with the international studies in comparison to the study by Farooqui et al. (2007) which validates the findings of this study.
This analysis shows that apart from perception of contractors, other stakeholder groups greatly vary in their assessment of delay causes in different regions, especially that for the client group. Moreover, slow decision making by the client was found to be a highly ranked factor consultants and contractors in all regions. Changes in design or scope of project (change orders) were found to be the other highly ranked causes by architects, contractors and consultant.

\subsection{Stakeholders' perspective on remedies of delays}

Table 3 shows the top ten remedies to delay identified by each stakeholder on the basis of FI. The values are arranged in descending order of FI. The architects have ranked the accuracy and timeliness of provision of design, and selection of competent design consultant and project manager as the top three (03) remedial measures for the delays in construction projects. So, according to this group, these remedies can solve the issues of funds allocation and availability and frequent design changes which were the top ranked causes of delay by them.

The clients' group has ranked selection of competent sub-contractor, suppliers and project managers and proper planning of project as the top remedies for reducing project delays. These observations are similar to those by architects' group which have also emphasized on selection of competent team members. These remedies can also be linked to the high ranking causes of delays by the clients, which included mobilization of labor and improper planning. Hence, clients perceive that competent team members can overcome these problems through their skill and experience.

According to consultants' group, selection of competent design consultant, proper site 
management and supervision and use of modern equipment are the top priority remedies for delays. Selection of competent personnel is the recurring top remedy which has been specified by architects as well as clients. Consultants' group also mentioned the inadequacy of selection procedure (such as awarding to lowest bidder) to be the major cause of delay. In addition, the consultants' group has also emphasized on the use of modern equipment to avoid delays in projects. It is notable that the construction industry in Pakistan currently lacks in this area for majority of its projects.
The contractors' group has ranked proper site supervision, selection of competent design engineer and proper planning and scheduling as the top remedies for delays. The first two (02) were also highlighted by the consultants' group, while proper planning is also mentioned by the clients' group. Therefore, it can be said that contractors perceive that competent design engineers and proper planning can reduce the change orders and inaccurate time estimation which were among the major causes of delays by them.

Table 3: Top ten remedies to delays from the architect's perspective

\begin{tabular}{|c|c|}
\hline Remedies to Delays & F.I \\
\hline \multicolumn{2}{|l|}{ Architect's Perspective } \\
\hline Complete and proper design at the right time & 245 \\
\hline Competent personnel of consultant/designer & 245 \\
\hline Competent project manager & 205 \\
\hline Ensure adequate and available source of finance until project completion & 195 \\
\hline Clear information and communication channels & 190 \\
\hline Frequent coordination between the parties & 180 \\
\hline Proper project planning and scheduling & 155 \\
\hline Accurate initial time estimates & 145 \\
\hline Effective strategic planning & 140 \\
\hline Accurate initial cost estimates & 140 \\
\hline Complete and accurate project feasibility study and site investigation & 140 \\
\hline Multidisciplinary/competent project team & 140 \\
\hline \multicolumn{2}{|l|}{ Client's Perspective } \\
\hline Use of experienced subcontractors and suppliers & 400 \\
\hline Perform a preconstruction planning of project tasks and resource needs & 260 \\
\hline Competent project manager & 244 \\
\hline Proper project planning and scheduling & 224 \\
\hline Comprehensive contract administration & 212 \\
\hline Site management and supervision & 192 \\
\hline Use of appropriate construction methods & 192 \\
\hline Systematic control mechanism & 176 \\
\hline Use of proper and modern construction equipment & 172 \\
\hline Project management assistance & 160 \\
\hline \multicolumn{2}{|l|}{ Consultant's Perspective } \\
\hline Competent personnel of consultant/designer & 496 \\
\hline Site management and supervision & 458 \\
\hline Use of proper and modern construction equipment & 449 \\
\hline Competent and capable client's representative & 409 \\
\hline Competent project manager & 400 \\
\hline Complete and proper design at the right time & 398 \\
\hline Use up to date technology utilization & 398 \\
\hline Complete and accurate project feasibility study and site investigation & 393 \\
\hline Use of experienced subcontractors and suppliers & 387 \\
\hline Project management assistance & 382 \\
\hline \multicolumn{2}{|l|}{ Contractor's Perspective } \\
\hline Site management and supervision & 614 \\
\hline Competent personnel of consultant/designer & 590 \\
\hline Proper project planning and scheduling & 554 \\
\hline Accurate initial cost estimates & 536 \\
\hline Awarding bids to the right/experience consultant and contractor & 509 \\
\hline Use of proper and modern construction equipment & 506 \\
\hline Proper material procurement & 471 \\
\hline Complete and proper design at the right time & 466 \\
\hline Developing human resources in the construction industry & 465 \\
\hline Competent and capable client's representative & 450 \\
\hline
\end{tabular}

Table 4 shows the common rankings of factors which were commonly preferred by multiple stakeholder groups. There is more consensus among stakeholder groups with regards to the remedies for delays as most of the top ranking remedies are found to be common in three (03) out of four (04) stakeholder groups. These include selection of competent personnel, proper project planning and scheduling, timely provision of complete design, proper site supervision and use of modern equipment. These remedies complement the top causes of delays which have involved incomplete design, incompetency of project team and improper scheduling and planning.

\subsection{ANOVA for causes of delays}

Table 5 shows that the means of the AR, CL, CONS and CONT for the causes of delay are 3.02, 2.20, 2.80 and 3.03 respectively. ANOVA was performed to 
know whether the observed difference between the sample means for the causes of delay is significant or not. The results for ANOVA are shown in Table 6. The $\mathrm{P}$-value obtained from the ANOVA $(0.000)$ is less than the $\alpha$-value $(0.05)$ at $95 \%$ confidence interval, so the following null hypothesis is rejected:

$\mu_{A R}=\mu_{C L}=\mu_{C O N S}=\mu_{C O N T}$

Table 4: Common causes and remedies of delays

\begin{tabular}{|c|c|c|c|c|}
\hline Causes & $\mathrm{AR}$ & CL & CONS & CONT \\
\hline Constraints to client (bank loans, funds, taxes etc) & $\bullet$ & $\bullet$ & & $\bullet$ \\
\hline Client's financial difficulties (missing) & $\bullet$ & & & $\bullet$ \\
\hline Frequent design changes & $\bullet$ & & & $\bullet$ \\
\hline Delay payment to supplier/subcontractor & $\bullet$ & & & $\bullet$ \\
\hline Incomplete construction drawings (shop drawings) & $\bullet$ & & $\bullet$ & $\bullet$ \\
\hline Improper project planning \& scheduling & & $\bullet$ & $\bullet$ & \\
\hline Slow decision making by client & & & $\bullet$ & $\bullet$ \\
\hline Incomplete drawing/details design & & & $\bullet$ & $\bullet$ \\
\hline Remedies & AR & CL & CONS & CONT \\
\hline Competent Project Manager & $\bullet$ & $\bullet$ & $\bullet$ & \\
\hline Proper project planning and scheduling & $\bullet$ & $\bullet$ & & $\bullet$ \\
\hline Competent personnel of consultant/designer & $\bullet$ & & $\bullet$ & $\bullet$ \\
\hline Complete and proper design at the right time & $\bullet$ & & $\bullet$ & $\bullet$ \\
\hline Accurate initial cost estimates & $\bullet$ & & & $\bullet$ \\
\hline Use of experienced subcontractors and suppliers & $\bullet$ & $\bullet$ & $\bullet$ & \\
\hline Site management and supervision & & $\bullet$ & $\bullet$ & $\bullet$ \\
\hline Use of proper and modern construction equipment & & $\bullet$ & $\bullet$ & $\bullet$ \\
\hline Project management assistance & & $\bullet$ & $\bullet$ & \\
\hline Competent and capable client's representative & $\bullet$ & & $\bullet$ & $\bullet$ \\
\hline Complete and accurate project feasibility study and site investigation & $\bullet$ & & $\bullet$ & \\
\hline
\end{tabular}

Table 5: Descriptive statistics for rankings of all stakeholders for causes and remedies of delays

\begin{tabular}{|c|c|c|c|}
\hline Level & Sample Size "N" & Mean & Standard Deviation \\
\hline \multicolumn{4}{|c|}{ Causes } \\
\hline Architect & 81 & 3.0230 & 0.7149 \\
\hline Client & 81 & 2.2069 & 0.7646 \\
\hline Consultant & 81 & 2.8391 & 0.5029 \\
\hline Contractor & 81 & 3.0345 & 0.6185 \\
\hline \multicolumn{4}{|c|}{ Remedies } \\
\hline Architect & 35 & 3.4357 & 0.6512 \\
\hline Client & 35 & 3.2514 & 0.6368 \\
\hline Consultant & 35 & 3.6897 & 0.3901 \\
\hline Contractor & 35 & 3.2809 & 0.3392 \\
\hline
\end{tabular}

Hence there is significant difference between the sample means for the causes of delay but the rejection of Null Hypothesis does not tell us where the difference lies. It is clear from Fig. 5, which is a box plot for ranking of causes of delay that the clients is outlier i.e. the distribution of ranking for the causes of delays of the client is totally differing from the rest of the respondents. This trend is also reinforced by the fact that the mean for client group is the lowest with a higher standard deviation. This reiterates the fact that client's perception regarding causes of delays is more distributed compared to all other stakeholders. So, ANOVA was carried out again after excluding the client group to find whether there is a significant level of agreement between the means of architect, consultant and contractor groups.

ANOVA results after excluding client are given in Table 7. It shows that $\mathrm{P}$-value obtained from this ANOVA (0.067) is greater than the $\alpha$-value $(0.05)$ at $95 \%$ confidence interval, so the null hypothesis is accepted. There is significant agreement between the sample means for the causes of delay among other stakeholders except clients.

Table 6: ANOVA for all stakeholders for causes and remedies of delays

\begin{tabular}{|c|c|c|c|c|c|}
\hline Source of Variation & Degree of Freedom & Sum of Squares & Mean Square & F-Ratio & P-Value \\
\hline \multicolumn{6}{|c|}{ Causes } \\
\hline Factor & 3 & 39.644 & 13.215 & 30.53 & 0.000 \\
\hline Error & 344 & 148.874 & 0.433 & & \\
\hline Total & 347 & 188.517 & & & \\
\hline \multicolumn{6}{|c|}{ Remedies } \\
\hline Factor & 3 & 4.223 & 1.408 & 5.13 & 0.002 \\
\hline Error & 136 & 37.291 & 0.274 & & \\
\hline Total & 139 & 41.514 & & & \\
\hline
\end{tabular}

Table 7: ANOVA for all stakeholder groups (except client) for causes of delays

\begin{tabular}{cccccc}
\hline Source of Variation & Degree of Freedom & Sum of Squares & Mean Square & F-Ratio & P-Value \\
\hline Factor & 2 & 2.092 & 1.046 & 0.067 \\
Error & 258 & 98.598 & 0.382 & \\
Total & $\mathbf{2 6 0}$ & $\mathbf{1 0 0 . 6 9 0}$ & & \\
\hline
\end{tabular}




\subsection{ANOVA for remedies to delays}

Table 5 shows that the means of the stakeholders' group rankings for the remedy to delay are 3.4, 3.3, 3.7 and 3.3 respectively. Once again, ANOVA was performed to investigate whether the observed difference between the sample means for the remedy to delay is significant or not. Table 6 shows the result of this ANOVA. The P-value obtained from the Analysis (0.002) is less than the $\alpha$-value (0.05) at $95 \%$ confidence interval, so the null hypothesis is rejected:

$\mu_{A R}=\mu_{C L}=\mu_{C O N S}=\mu_{C O N T}$

The rejection of Null Hypothesis does not tell us where the difference lies, so looking at Fig. 6 (box plot for ranking of remedies of delays), it can be observed that the consultant is the outlier i.e. the distribution of rankings for the remedies of delays of the consultant is differing from the rest of the respondents. It can also be observed from the data of Table 5 that consultant group has a highest mean value with a relatively low standard deviation. So the consultant group was excluded from ANOVA to find whether there is a significant level of agreement between the means of architect, client and contractor groups.

Table 8 shows the results of this ANOVA after excluding consultants' group mean. The P-value obtained from the ANOVA (0.34) is greater than the $\alpha$-value $(0.05)$ at $95 \%$ confidence interval, so the null hypothesis is accepted i.e. there is significant agreement between the sample means for the remedies of delay.

\section{Conclusion}

This research had two main objectives which were; to rank the major causes of and remedies of delays in building construction industry and to compare the rankings for different stakeholders with local and international scenarios in developing countries. From this research, the top 10 identified factor causing delays included financial difficulties of the client, lack of decision making power of the client, selection of inexperienced/unqualified team members, incomplete shop drawings, poor site management and supervision and inaccurate estimation of time. Among these factors, poor site management has also been considered to be the factor causing construction delay in developed as well as developing countries.

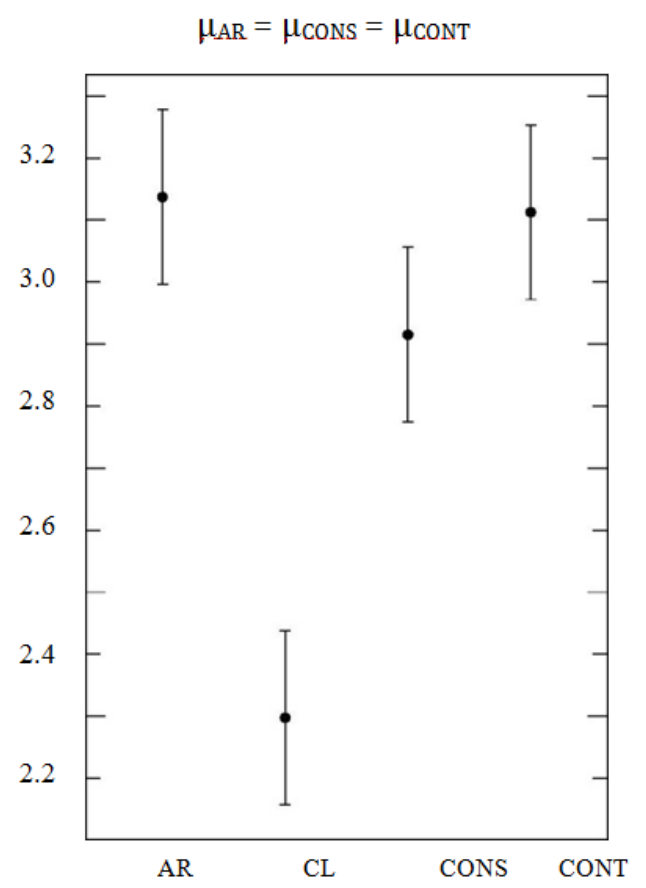

Fig. 5: Box plot for the cause of delays for all stakeholders

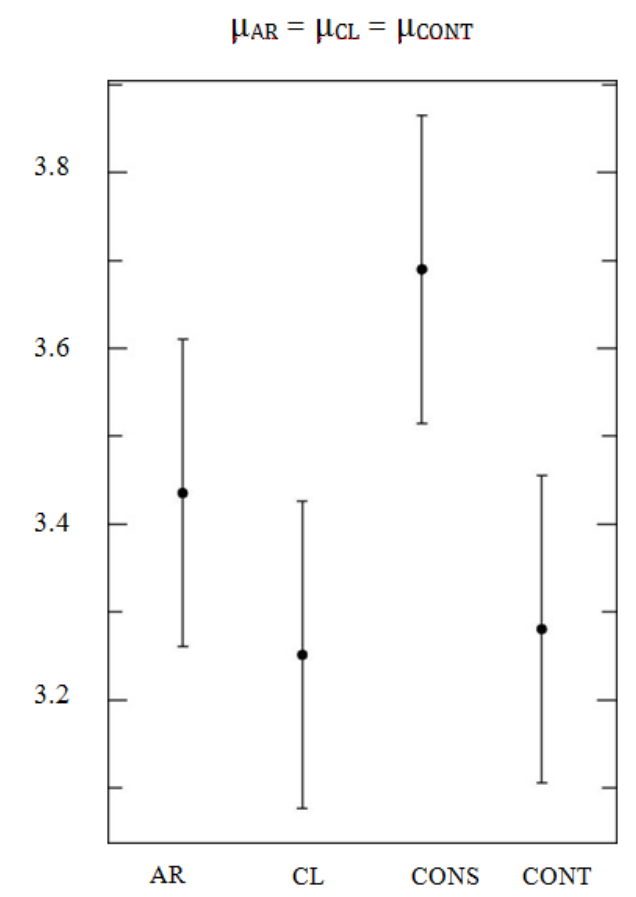

Fig. 6: Box plot for the remedies of delays for all stakeholders

Table 8: ANOVA of all stakeholder groups (except consultant) for remedies of delays

\begin{tabular}{cccccc}
\hline Source of Variation & Degree of Freedom & Sum of Squares & Mean Square & F-Ratio & P-Value \\
\hline Factor & 2 & 0.686 & 0.343 & 1.09 & 0.340 \\
Error & 102 & 32.118 & 0.315 & & \\
Total & $\mathbf{1 0 4}$ & $\mathbf{3 2 . 8 0 4}$ & & & \\
\hline
\end{tabular}

For Remedies to delays, it was concluded form this research that competent project manager is very essential for avoiding delays because they are inevitable for proper planning and scheduling. In addition, selection of skilled and qualified contractors, consultants and suppliers, usage of modern equipment, availability of financial resources of the client, and proper site supervision, were the best remedies to delays indicated by this research. 
It was also found that the perception of clients varies greatly in the local industry in comparison with other construction industries. However, the contractors' perception was found to be highly similar in this regard with the international market. Another aspect of this research was to statistically analyze the difference in perception of these stakeholders regarding factors causing delays and their remedies. It was found that clients have a more varying perspective than the other stakeholder groups. In the context of remedies, consultant group was found to be the outlier in comparison with the perception of other stakeholders.

Through this study, following points can be recommended, which were agreed by all stakeholders in order to minimize and control delays in building construction projects. Project team selection is the first and foremost priority in which the traditional method of awarding to the lowest bidder is not efficient. Architect/Design Engineer should focus on the timely and accurate preparation of design documents. In addition to that, regular site supervision and monitoring is also essential. Clients/Owners should give special attention to approval and disbursement of design and payments, minimizing change orders during construction and resources and capabilities of contractor/subcontractor before awarding the contract. Contractors should consider avoiding shortage and low productivity of labor, financial and cash flow problems, continual planning and scheduling, assigning suitable staff for site management and supervision, and up gradation of human resource capacity through continuous worktraining programs for construction personnel.

The future direction of research for this work could be the evaluation of remedial measures for coping with delay causing factors. Furthermore, the delay causing factors in other types of construction projects should also be identified and ranked using the methodology outlined in this study.

\section{References}

Aibinu AA and Jagboro GO (2002). The effects of construction delays on project delivery in Nigerian construction industry. International Journal of Project Management, 20(8): 593-599.

Alinaitwe H, Apolot R, and Tindiwensi D (2013). Investigation into the causes of delays and cost overruns in Uganda's public sector construction projects. Journal of Construction in Developing Countries, 18(2): 33-47.

Al-Momani AH (2000). Construction delay: a quantitative analysis. International Journal of Project Management, 18(1): 51-59

Assaf SA, Al-Khalil M, and Al-Hazmi M (1995). Causes of delay in large building construction projects. Journal of Management in Engineering, 11(2): 45-50.
Chidambaram R, Narayanan SP, and Idrus AB (2012). Construction delays causing risks on time and cost-a critical review. Construction Economics and Building, 12(1): 37-57.

Doloi H, Sawhney A, Iyer KC, and Rentala S (2012). Analysing factors affecting delays in Indian construction projects. International Journal of Project Management, 30(4): 479-489.

Farooqui RU, Ahmed SM, and Saqib M (2007). Delays in construction-an empirical study of contractors' perceptions in Pakistan construction industry. In the $4^{\text {th }}$ International Conference on Construction in the 21st Century: Accelerating Innovation in Engineering, Management and Technology (CITC IV 2007), Gold Coast, Australia, 437: 11-13.

Halwatura RU and Ranasinghe NPNP (2013). Causes of variation orders in road construction projects in Sri Lanka. ISRN Construction Engineering, 2013: Article ID 381670, 7 pages. https://doi.org/10.1155/2013/381670

Herbsman ZJ, Tong Chen W, and Epstein WC (1995). Time is money: Innovative contracting methods in highway construction. Journal of Construction Engineering and Management, 121(3): 273-281.

Hwang BG, Zhao X, and Ng SY (2013). Identifying the critical factors affecting schedule performance of public housing projects. Habitat International, 38: 214-221.

Kikwasi G (2013). Causes and effects of delays and disruptions in construction projects in Tanzania. In Australasian Journal of Construction Economics and Building-Conference Series, 1(2): 52-59.

Koushki PA, Al-Rashid K, and Kartam N (2005). Delays and cost increases in the construction of private residential projects in Kuwait. Construction Management and Economics, 23(3): 285-294.

Kumaraswamy MM and Chan DW (1998). Contributors to Construction Delays. Construction Management and Economics, 16(1): 17-29.

Majid MA and McCaffer R (1998). Factors of non-excusable delays that influence contractors' performance. Journal of Management in Engineering, 14(3): 42-49.

Marzouk MM and El-Rasas TI (2014). Analyzing delay causes in Egyptian construction projects. Journal of Advanced Research, 5(1): 49-55.

Memon AH, Rahman IA, and Azis AAA (2012). Time and cost performance in construction projects in southern and central regions of Peninsular Malaysia. International Journal of Advances in Applied Sciences, 1(1): 45-52.

Mezher TM and Tawil W (1998). Causes of delays in the construction industry in Lebanon. Engineering, Construction and Architectural Management, 5(3): 252-260.

Odeh AM and Battaineh HT (2002). Causes of construction delay: traditional contracts. International Journal of Project Management, 20(1): 67-73.

Santoso DS and Soeng S (2016). Analyzing delays of road construction projects in Cambodia: Causes and effects. Journal of Management in Engineering, 32(6): 05016020. https://doi.org/10.1061/(ASCE)ME.1943-5479.0000467

Wiguna IPA and Scott S (2003). Analyzing the risks affecting construction delay and cost overruns in Indonesia building projects. In the $2^{\text {nd }}$ International Conference on Innovation in Architecture, Engineering and Construction. Loughborough, UK: 841-849. 